\title{
Morphological Investigation into Starch Bio-Nanocomposites via Synchrotron Radiation and Differential Scanning Calorimetry
}

\author{
Huihua Liu, Deeptangshu Chaudhary, Joseph John, and Moses O. Tadé \\ Department of Chemical Engineering, Curtin University, Perth, WA 6102, Australia \\ Correspondence should be addressed to Deeptangshu Chaudhary, d.chaudhary@curtin.edu.au \\ Received 11 March 2011; Accepted 24 May 2011 \\ Academic Editor: Valery Khabashesku \\ Copyright () 2011 Huihua Liu et al. This is an open access article distributed under the Creative Commons Attribution License, \\ which permits unrestricted use, distribution, and reproduction in any medium, provided the original work is properly cited.
}

\begin{abstract}
We studied a hydrophilic, plasticized bionanocomposite system involving sorbitol plasticizer, amylose biopolymer, and montmorillonite (MMT) for the presence of competitive interactions among them at different moisture content. Synchrotron analysis via small angle X-ray scattering (SAXS) and thermal analysis using differential scanning calorimetry (DSC) were performed to understand crystalline growth and the distribution of crystalline domains within the samples. The SAXS diffraction patterns showed reduced interhelix spacing in the amylose network indicating strong amylose-sorbitol interactions. Depending on the sorbitol and MMT concentration, these interactions also affected the free moisture content and crystalline domains. Domains of around $95 \AA$ and $312 \AA$ were found in the low-moisture-content samples as compared to a single domain of $95 \AA$ in the high-moisture-content samples. DSC measurements confirmed that the MMT increased the onset and the melting temperature of nanocomposites. Moreover, the results showed that the ternary interactions among sorbitol-amylose-MMT supported the crystalline heterogeneity through secondary nucleation.
\end{abstract}

\section{Introduction}

Starch is a widely studied biopolymer because of its biodegradable and renewable nature, as well as its comparable mechanical properties to many polyolefins. However, its high glass transition temperature and water sensitivity limit its utilization in environmentally friendly applications such as flexible packaging for food/horticultural products. A significant turn-around in commercial acceptance with key commercial and environmental benefits can be achieved through judicial balance of molecular interactions within the hydrophilic environment of a plasticized amylose biopolymer system. The authors had earlier reported on starch biopolymer processing [1] and hydrophilic interactions in starch and various additives [2]. Interactions between glycerol and starch nanocomposites, for example, glycerol/starch/MMT $[3,4]$ and the competitive interaction between starch/MMT (unmodified montmorillonite)/water system have also been reported [5]. Those investigations outlined that the hydrophilic interactions between an amylose polymer and different plasticizers are typically concentration dependent. It was also summarized that the interactions between the larger amylose polymer and the smaller water/glycerol molecules are stronger as compared to the starch-MMT interactions because of the relatively smaller size of glycerol molecules. Therefore, this investigation focuses on the hypothesis that with larger plasticizer molecules such as in a starch/MMT/ sorbitol system, where the sorbitol molecule is larger than glycerol, interactions between water and sorbitol would become competitive for certain sorbitol concentrations. Further, in the presence of nanoparticles such as MMT, such interactions would lead to the formation of different morphologies and size domains, which may alter the bulk crystallinity and stabilize the bulk mechanical properties [6]. Since physical properties such as strength and modulus are related to bulk crystallinity and glass transition behavior, an understanding of these interactions is crucial for developing flexible packaging products.

small angle X-ray scattering (SAXS) is a powerful and efficient method to investigate the dispersion of nanoscale particles and crystal domain sizes that are formed due to the interactions between the polymer and other additives with a structural size of $10 \AA$ or larger [7]. Several methods have been developed for extracting SAXS related parameters 
TABLE 1: Experimental sheet for sample preparation and characterization results (moisture content, characteristic peak position, and basal spacing). The standard deviation (SD) for the moisture measurement and for the basal spacing is less than $0.6 \%$.

\begin{tabular}{|c|c|c|c|c|c|c|c|c|c|c|}
\hline \multicolumn{5}{|c|}{ High-moisture-content samples } & \multicolumn{5}{|c|}{ Low-moisture-content samples } & \multirow{2}{*}{$\Delta d^{*}$} \\
\hline Sample ID & $\begin{array}{c}\text { Moisture } \\
(\%)\end{array}$ & $\begin{array}{c}P_{\mathrm{MMT}} \\
\left(\mathrm{nm}^{-1}\right)\end{array}$ & $\begin{array}{c}P_{\text {starch }} \\
\left(\mathrm{nm}^{-1}\right)\end{array}$ & $\begin{array}{c}\text { Basal spacing } \\
(\AA)\end{array}$ & Sample ID & $\begin{array}{l}\text { Moisture } \\
(\%)\end{array}$ & $\begin{array}{c}P_{\mathrm{MMT}} \\
\left(\mathrm{nm}^{-1}\right)\end{array}$ & $P_{\text {starch }}\left(\mathrm{nm}^{-1}\right)$ & $\begin{array}{c}\text { Basal spacing } \\
(\AA)\end{array}$ & \\
\hline PS & 30.69 & - & 0.36 & - & OPS & 2.2 & - & 0.368 & & \\
\hline S010 & 26.23 & - & 0.36 & - & OS010 & 2.71 & - & 0.358 & & \\
\hline S020 & 16.68 & - & 0.36 & - & OS020 & 2.14 & - & 0.355 & & \\
\hline S105 & 30.32 & 0.292 & 0.363 & 21.5 & OS105 & 2.38 & 0.423 & 0.358 & Exfoliated & - \\
\hline S115 & 17.31 & 0.3 & 0.360 & 20.9 & OS115 & 4.83 & 0.315 & - & 19.9 & 1.0 \\
\hline S200 & 20.13 & 0.290 & 0.36 & 21.7 & OS200 & 6.19 & 0.423 & - & 14.7 & 7 \\
\hline S210 & 28.46 & 0.295 & Shoulder & 21.3 & OS210 & 3.23 & 0.317 & - & 19.8 & 1.5 \\
\hline S220 & 21.93 & 0.302 & Shoulder & 20.8 & OS220 & 4.53 & 0.310 & & 20.3 & 0.5 \\
\hline S305 & 27.59 & 0.304 & Shoulder & 20.7 & OS305 & 3.52 & 0.422 & 0.36 & Exfoliated & \\
\hline S315 & 22.98 & 0.295 & Shoulder & 21.3 & OS315 & 2.53 & 0.311 & - & 20.2 & 2.1 \\
\hline S400 & 18.47 & 0.381 & 0.36 & Exfoliated & OS400 & 5.67 & 0.421 & - & Exfoliated & - \\
\hline S410 & 25.93 & 0.290 & Shoulder & 21.7 & OS410 & 2.45 & 0.309 & - & 20.3 & 1.4 \\
\hline S420 & 15.61 & 0.295 & Shoulder & 21.3 & OS420 & 2.07 & 0.302 & - & 20.8 & 0.5 \\
\hline
\end{tabular}

$P_{\mathrm{MMT}}$ : characteristic peak of nanoclay in corresponding nanocomposite.

$P_{\text {starch }}$ : characteristic peak of starch in corresponding nanocomposite.

Basal spacing: gallery spacing calculated from the Bragg equation.

$\Delta d^{*}$ : basal spacing (high moisture content) - basal spacing (low moisture content).

including Benjamin's novel method for estimating structural parameters and crystal thickness [8-10]. But for amylosebased nanocomposites, the interactions between amylose polymer/MMT/plasticizer/water are complicated by the polymers' humidity sensitivity and thus, these interactions are still not well understood [11-13].

This is the first report on high-amylose based sorbitolplasticized nanocomposites where we examine the combined effect of sorbitol concentration and MMT loading on the size distribution profile of the crystalline domains. The discussions of the obtained data were organized with the aim to understand the synergistic interactions of the prepared nanocomposites. Thus we discussed the binary composite which consisted of only starch and either sorbitol or MMT (SAXS, via the Synchrotron radiation facility in SPring-8 (Hyogo, Japan)) followed by comprehensive analysis on the more complicated ternary composites (starch + sorbitol + MMT) via both size distribution calculation (based on entropy maximum method) and Calorimetry technique (via Differential Scanning Calorimetry).

\section{Materials and Method}

2.1. Materials and Extrusion. Amylose starch (70\% amylose) was purchased from National Starch Company (New Jersey, USA); sorbitol was obtained from Food Dept Melbourne Company (Melbourne, Australia); MMT (natural $\mathrm{Na}^{+}$-montmorillonite, $99.5 \%$ ) was supplied by NichePlas Ltd. (Sydney, Australia). This platelet type MMT has been studied extensively in polyolefinic polymers (oil based polymers), because of their increased physical and gas barrier properties. However, for hydrophilic biopolymeric systems, such as for amylose-rich starch polymers, because its bulk crystallinity is affected by moisture, the interactions of MMT with amylose and with plasticizers need to be considered in the presence of water. Two sets of samples were prepared for the synchrotron SAXS measurement, namely the high moisture content and low moisture content samples, where samples around 3-4 $\mathrm{g}$ from each formulation were equilibrated under different moisture environments for characterization and testing. The different formulations were prepared on a twin screw co-rotating extruder; please refer to our previous report for detailed processing parameters [5]. The high moisture content samples were the extruded samples that were maintained at $25^{\circ} \mathrm{C}$ for 30 minutes followed by vacuum sealing and freezing at $-20^{\circ} \mathrm{C}$ for synchrotron and calorimetric measurements. The low moisture samples were prepared from the extruded samples, where samples between 3 and $4 \mathrm{~g}$ (in triplicates) were maintained at $60^{\circ} \mathrm{C}$ for 12 hours and then vacuum sealed and frozen at $-20^{\circ} \mathrm{C}$. The reason for storing at such a low temperature (below glass transition temperature) was to prevent any molecular reorganization due to small scale polymer chain movement. In this paper, the nomenclature was indicated as the sequence of "humidity condition", "plasticizer name", "MMT concentration" and "plasticizer concentration"; for example, for sample OS105, "O" referred to the low moisture content samples, " $\mathrm{S}$ " was the sorbitol plasticizer and "1" referred to the wt $\%$ of MMT. The last two digits- " 05 " referred to the wt $\%$ of sorbitol. The samples were maintained in triplicates and their formulations were listed in Table 1 where PS referred to the pure starch sample.

2.2. Characterization Studies. Small Angle X-ray Scattering was carried out at beamline BL40B2 of Spring-8 synchrotron 
facility in Hyogo, Japan. For detailed information on beamline BL40B2, please refer to Inoue et al.'s publication [14]. The beam was monochromatized to a wavelength value of $0.1 \mathrm{~nm}$ with an object distance of $1151.767 \mathrm{~mm}$. All patterns were recorded on a CCD camera, which was calibrated by the diffraction rings from $\mathrm{AgBH}$ (Silver Behenate) reference sample. An aluminum filter block was employed to decrease the strength of X-ray so as to obtain optimized pattern. The measurement time per sample was chosen to eliminate the radiation damage on tested samples, and subsequently determined as 10 seconds. The data reductions of the obtained 2-D X-ray scattering patterns were processed with NIKA macros [15] based on Igor 6.02 (Wavemetrics, Lake Oswego, Oregon). All plots were recorded after the subtraction of instrument background.

Thermal measurements using Differential Scanning Calorimetry (DSC) were performed on approximately $8 \mathrm{mg}$ of samples using SEIKO 6200 (Seiko, Japan) with its customized analytical software. The samples were heated from $-50^{\circ} \mathrm{C}$ to $200^{\circ} \mathrm{C}$ at a heating rate of $5^{\circ} \mathrm{C} / \mathrm{min}$, and were maintained at $250^{\circ} \mathrm{C}$ for 5 minutes and then they were cooled to $25^{\circ} \mathrm{C}$ at $10^{\circ} \mathrm{C} / \mathrm{min}$. Using traditional measurement techniques, the glass transition temperature $\left(T_{g}\right)$ was taken as the inflection point of the increment of specific heat capacity. The melting temperature was recorded for analysis as well. Finally, a moisture meter (CA-100, Mitsubishi Chemical Corporation, Japan) was used to measure the absolute moisture content for all samples. Each measurement was conducted at least three times and the averaged value was recorded. Transmission electron microscopy (TEM) was performed on ultrathin sections on JEX-2100 microscope (JEOL, Tokyo, Japan), operating at an accelerating voltage of $120 \mathrm{kV}$. Only the low moisture content samples could be sectioned at room temperature with a diamond knife at Leica Ultramicrotome (EM UC7, Tokyo, Japan). Obtained sections of $150 \mathrm{~nm}$ thickness were sandwiched between two 300-mesh copper grids for TEM observation.

2.3. Size Distribution. Size distribution analysis of the crystalline domain is an important step in understanding the morphology within polymeric nanocomposite systems. The size distribution profiles for obtained samples were calculated according to an maximum entropy method (MEM) developed by Potton et al. [16] from Irena modeling macros [17]. For detailed description of the MEM, please refer to Potton et al.'s publication.

\section{Result and Discussion}

3.1. Moisture Measurement. Moisture measurements on the samples with and without MMT can indicate the influence of starch/plasticizer and starch/MMT interactions on the extent of moisture removal from the polymer matrix [18, 19]. Table 1 showed the moisture content for all the samples, along with the characteristic peak for the amylose interhelix and the average MMT basal spacing. It was observed that increasing sorbitol concentration typically reduced the amount of water within the polymer matrices by occupying some amylose-water interaction sites [5]. In the following sections, we discuss this behavior in detail using SAXS and DSC analysis.

The findings observed from the moisture measurement experiments were quite interesting. It was observed that the addition of sorbitol decreased the equilibrium moisture content in the low-humidity samples; for example, the moisture content for OS210 and S410 samples was found to be $3.23 \%$ and $2.45 \%$, respectively (Table 1 ). These results highlighted the strong amylose-sorbitol interaction which led to the replacement between water molecules by sorbitol molecules. However, in ternary nanocomposites, no obvious defined tendency about the relationship of equilibrium moisture content and the sorbitol/MMT was observed. For example, the samples with relative higher sorbitol content of $15-20 \mathrm{wt} \%$ but low clay content (from 1 to $4 \mathrm{wt} \%$ ) showed an increasing (S115/S315 and OS115/OS315) or decreasing trend (S220/S420 and OS220/OS420) of equilibrium moisture content. In other words, for the samples with low equilibrium moisture content, higher sorbitol amounts did not increase the $P_{\text {MMT }}$ values irrespective of the MMT concentrations. This behavior reflected increased amylose-sorbitol interactions (instead of amylose-amylose interactions) as the free/excess water molecules were replaced by the sorbitol molecules. On the other hand, the $P_{\text {MMT }}$ values progressively increased with increasing sorbitol concentration for the samples with high moisture content, which indicated that the sorbitol facilitated the migration of polymer and/or water into the galleries of the MMT. This was quite interesting because such behavior was directly related to the crystalline domains with the matrix and the development of a stable morphology. Thus, these key aspects were investigated in detail via SAXS analysis and calorimetry in the following sections.

\subsection{Synchrotron Results}

3.2.1. Pure Starch and Binary Composite Sample (Starch + Sorbitol and Starch + MMT). The background of the sample holder was subtracted from the raw patterns. The 2-D diffraction patterns for pure starch and binary composite samples (starch + sorbitol and starch + MMT) are shown in Figure 1. Correspondingly, the SAXS profiles are presented in Figure 2.

As shown in Figures 1(2) to 1(6), the diffraction patterns changed from circular (seen in PS) to elliptical with the addition of MMT (seen in S200/S400) and the presence of sorbitol (seen in S010/S020) decreased the diffraction intensities. Since the azimuth of the ellipse [20] reflected the influence of MMT loading and its orientation, the SAXS pattern revealed an increased lamella size with increasing MMT concentration, and such behavior had been shown earlier [21, 22]. Meanwhile, analyses of these raw patterns were carried out and the SAXS profiles for the pure amylose sample and its binary composite samples are shown in Figure 2. The diffraction intensity also highlighted the heterogeneities occurring across the polymeric network, and this was typically attributed to the electron-density heterogeneities [23]. It revealed that the higher intensities of S010/S020 and S200/S400 samples compared to those 

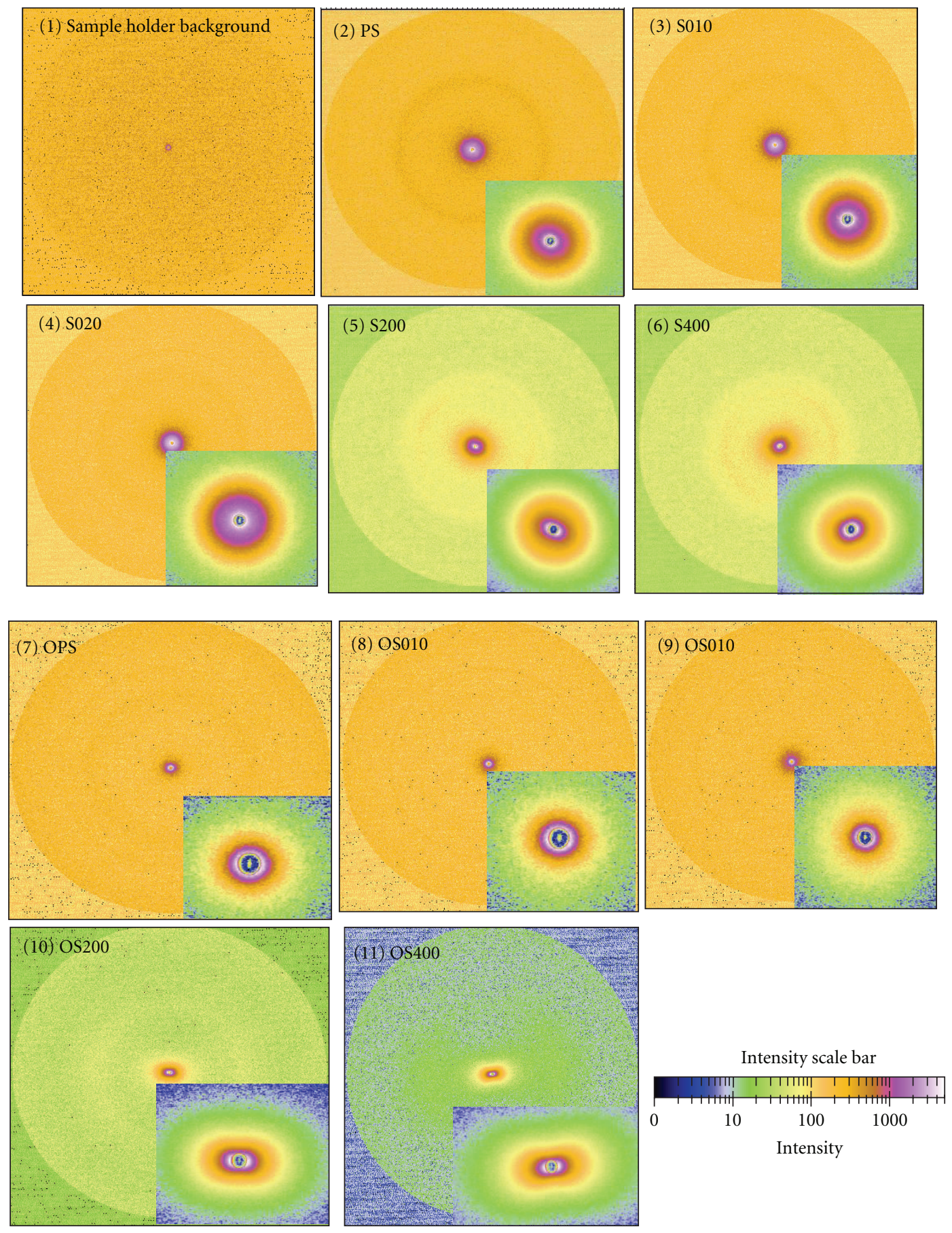

FIGURE 1: Raw diffraction patterns for pure starch, starch/sorbitol, and starch/nanoclay samples. (2)-(6) are high-moisture-content samples and (7)-(11) are low-moisture-content samples.

of PS were due to the larger lamellar morphology formed within the polymeric network. This strongly supported the argument that a crystalline-type growth was favored by the presence of sorbitol or MMT. Similarly, in the lowmoisture-content samples, greater ellipticity of the patterns indicated higher lamella heterogeneity across the samples. Such behavior had been reported by Grubb and Murthy in nylon-6 fibers during dehydration [24].
The interesting observation for OS020 sample was the "shoulder" located around $Q \approx 0.04-0.06 \AA^{-1}$, seen in Figure 2(b), which typically corresponded to a long periodic structure of the processed starch polymer [25]. Also, this long periodic structure of amylose is a characteristic of the moisture-rich samples, seen in Figure 2(a). So, for sample OS020, this unique feature suggested that its long periodic structure was preserved after drying treatment. Shamai 


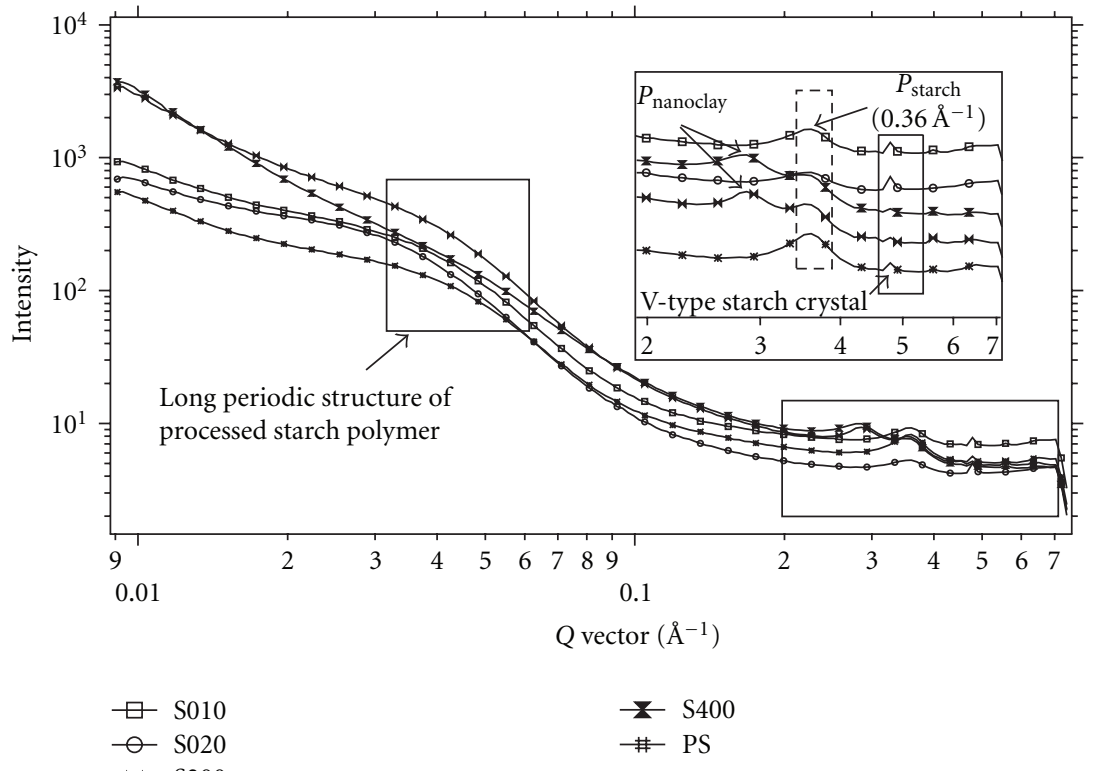

(a)

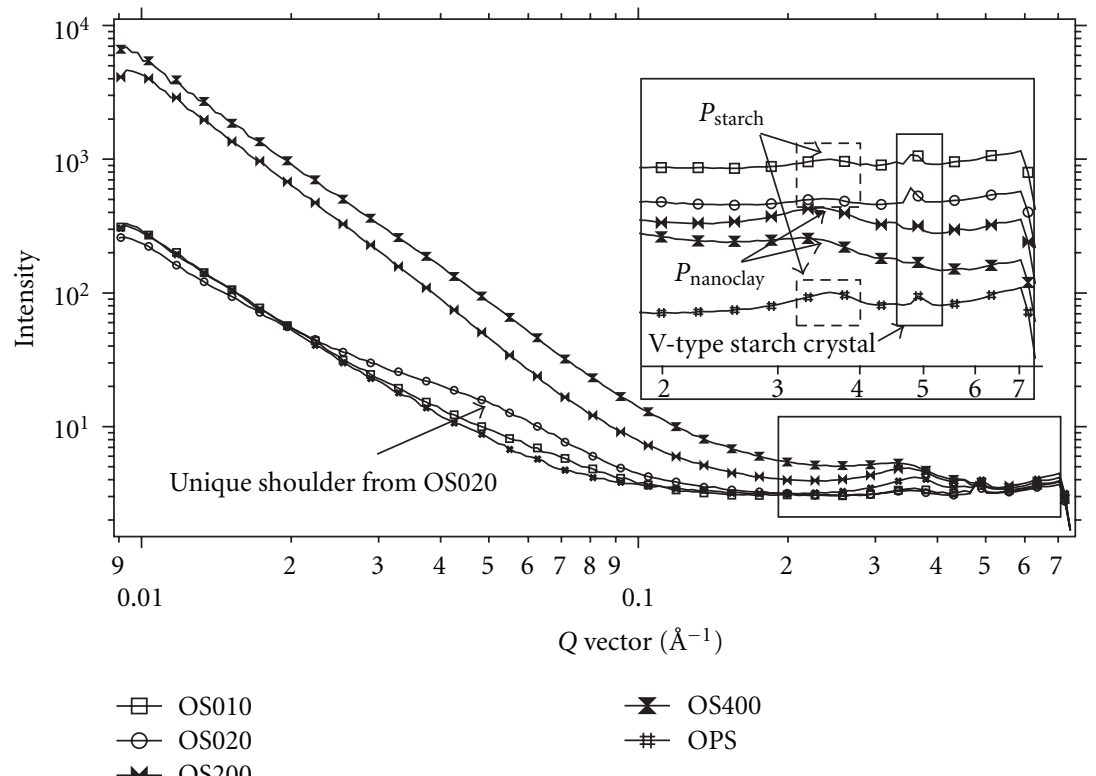

(b)

FIGURE 2: SAXS profiles for pure starch, starch/sorbitol, and starch/nanoclay samples (a) high-moisture-content and (b) low-moisturecontent samples generated from NIKA data processing software.

et al. [26] had earlier discussed the disappearance of a shoulder in the low-moisture-content starch samples and its influence on the retrogradation behavior. Thus, in the absence of moisture, this morphology was possible with strong amylose-sorbitol interactions that allowed the sorbitol molecules to replace the water molecules in amylose-water interaction sites.

The lack of the well-defined $9 \mathrm{~nm}\left(Q=0.07 \AA^{-1}\right)$ peak in the processed bio-nanocomposites and the appearance of a "shoulder" indicated a successful gelatinization process which destroyed the polymer organization and facilitated the polymer molecules to occupy the MMT galleries in the crystal's layers [27]. The characteristic peak for starch was assigned at $Q=0.36 \AA^{-1}$ and $Q=0.368 \AA^{-1}$ for the high- and low-moisture-content samples, respectively. These peaks corresponded to the 100 interhelix reflection of amylose polymer and were also typical of the B-type crystal [28]. These values were very similar to the observed values in Lopez-Rubio et al.'s investigation where they reported this peak value of extruded high-amylose maize starch at $Q=0.375 \AA^{-1}[29]$. The slight deviation between the two reported values was within expectation since the 100 


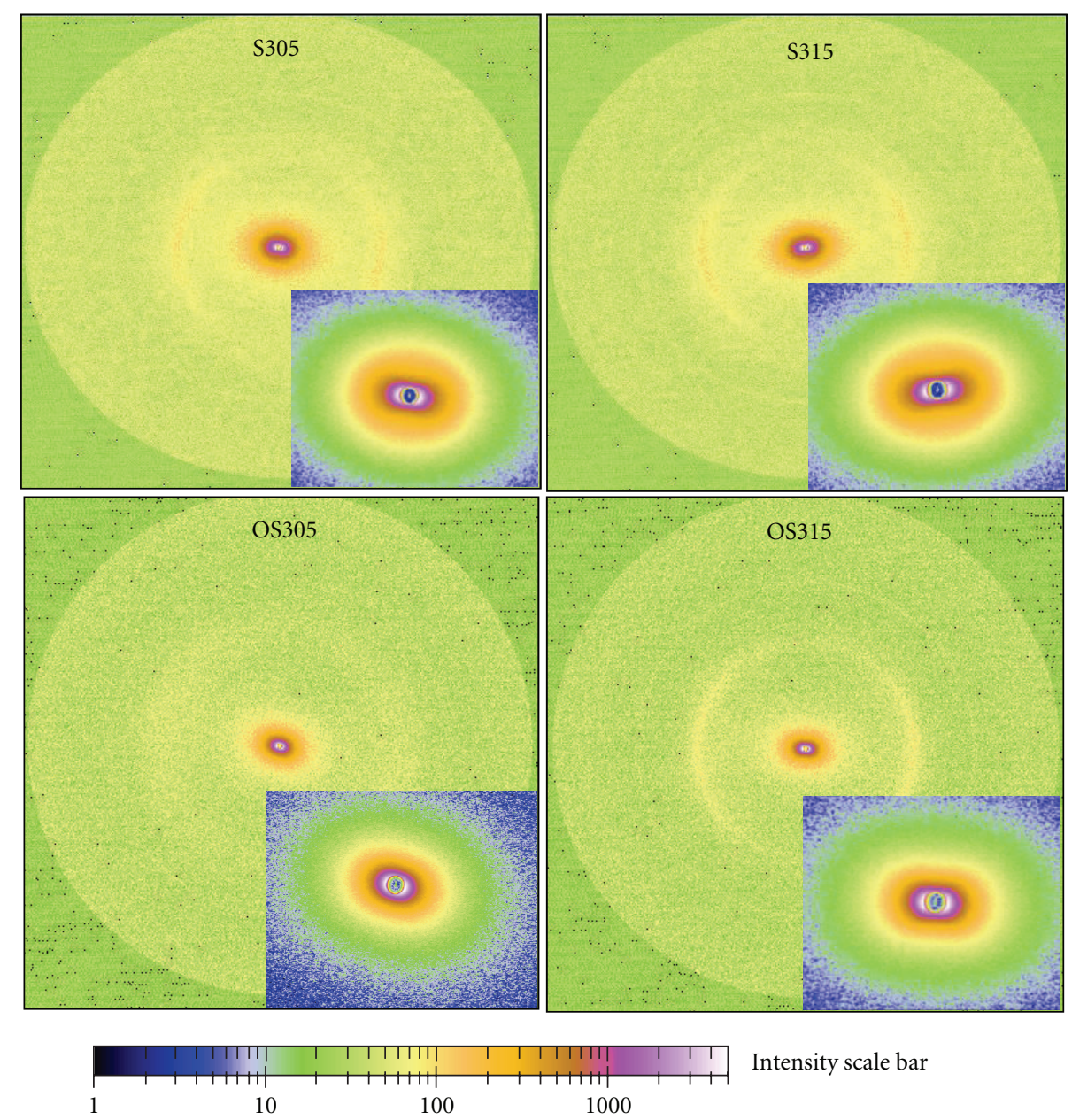

FIGURE 3: Raw diffraction patterns for selected ternary composites; S305, S315, OS305, and OS315.

peak was known to be related to the water content [30], and the deviation could be attributed to the difference in hydrated crystalline fractions within the 100 peak position. Using Bragg's calculation, the interhelix domain showed an increase from $17.1 \AA$ to $17.4 \AA$ upon hydration. This result was in agreement with Cleven et al.'s work where the diffraction peaks for B-type starch shifted toward greater lattice spacing with increasing hydration of the sample [31].

The Bragg peaks occurred at a series of $Q$ values satisfying the relationship $d \approx 2 \pi / q$. The corresponding basal spacing values are shown in Table 1 together with the characteristic parameters for each sample.

For the pristine MMT, the basal spacing value provided by the supplier is $11.7 \AA$. It could be read from Table 1 that the basal spacing value for S200 increased to $21.66 \AA$ after extrusion (the characteristic peak of MMT $\left(P_{\mathrm{MMT}}\right.$ ) located in $Q=0.290 \AA^{-1}$ ). This indicated that the starch chain had successfully penetrated into the gallery of MMT platelets $[32,33]$.

The characteristic peak of extruded amylose earlier discussed as $P_{\text {starch }}$ in Table 1 was a reflection of B-type crystalline morphology and this peak was found to decline upon the addition of sorbitol, as seen in Figure 2(b).
Further, the $P_{\text {starch }}$ also shifted to a lower $Q$ value indicating an enlarged interhelix spacing, confirming the sorbitol molecules were "held" tightly within the starch network under a low-moisture environment. Finally, analyzing the $P_{\text {MMT }}$ data presented in Table 1 and the peaks shown in Figure 2, it was seen that the removal of free water led to greater amylose-MMT intercalation (e.g., reduced basal spacing from $21.7 \AA$ (S200) to $14.7 \AA$ (OS200)) and similar results had been shown in the case of saponite hydration [34]. Meanwhile, the $P_{\text {starch }}$ for OS010 and OS020 showed $Q=$ $0.358 \AA^{-1}$ and $Q=0.355 \AA^{-1}$, respectively. Such observation pointed out the crucial role played by water molecules in modifying the interactions of starch and sorbitol at low equilibrium moisture content scenario.

\subsubsection{Competitive Interactions in the Ternary Composites} $($ Starch + Sorbitol $+M M T)$. The raw 2-D X-ray diffraction patterns for the representative ternary composite samples (amylase + sorbitol + MMT) are shown in Figure 3. Correspondingly, the SAXS profiles are presented in Figure 4.

Comparing the raw diffraction patterns for the binary composite samples (Figure 1) and the ternary composites samples (Figure 3), there is no intuitive distinctness that 


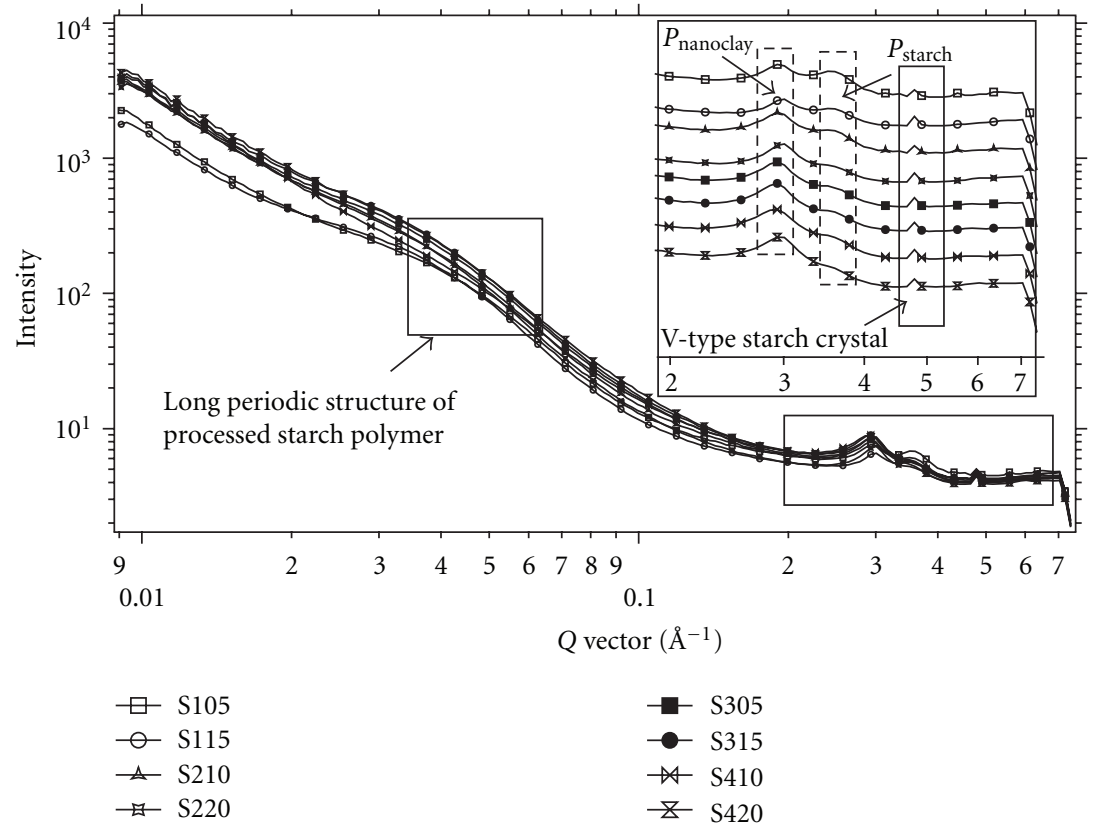

(a)

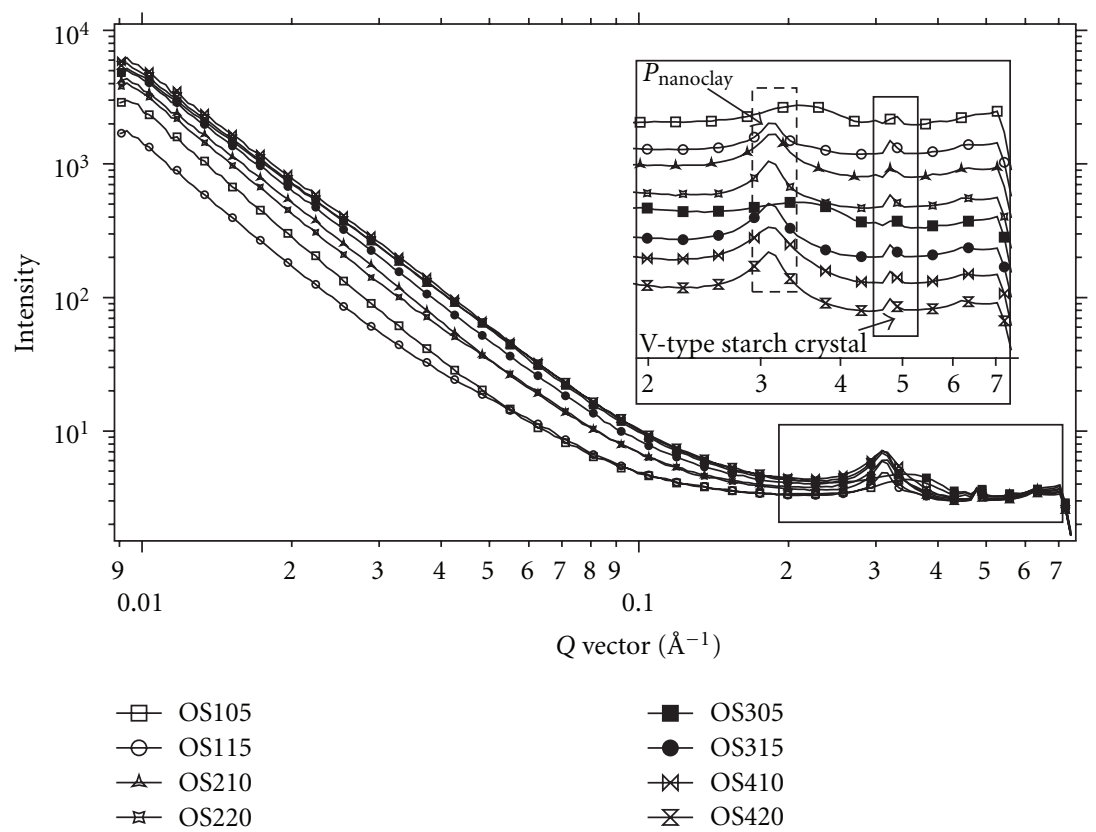

(b)

FIGURE 4: SAXS profiles for starch/sorbitol/nanoclay bionanocomposite samples (a) high-moisture-content and (b) low-moisture-content samples generated from NIKA data processing software.

can be observed. They shared the common features such as their elliptical shape and the ellipticity increased upon the removal of water. Thus, besides the discussions based on corresponding SAXS profiles (Table 1 and Figure 4), further analysis (the size distribution calculation) on the ternary composites had been carried out to gain a better understanding of the synergistic interactions within this complex system.
Within expectation, the intensity of scatter increased with the MMT loading for both sets of samples, as seen in Figure 4. As shown in Table 1, in all the samples, the $P_{\text {starch }}$ (100 interhelix distances) shifted to a lower value when the sorbitol concentration exceeded 15\%, regardless of the MMT loading. These results corroborated the hypothesis that there was a "threshold" sorbitol loading whereby the starchsorbitol interactions became dominant and that beyond 
this threshold concentration, its plasticization ability was unaffected by the loss of free water molecules [4].

It was interesting to see that all well-defined peaks in the low-moisture-content samples were absent, and, further, the peak for MMT basal distance and the 100 interhelix of polymer tended to overlap. This indicated the presence of short-range order within the biopolymer nanocomposite systems where the MMT hindered the amylose-sorbitol aggregation to further increase in their domain size.

The broad "shoulder" found in the high-moisturecontent samples, Figure 4(a), which typically related to the amylose gelatinization process disappeared in low-moisturecontent sample reflecting poorly organized amylose helix structures [35]. Shamai et al. had made the observation that small-scale polymeric reorganization due to retrogradation was typically presented in "shoulder" analysis [26] due to the loss of equilibrium moisture. The absence of shoulder in the low-moisture nanocomposites' profiles, Figure 4(b), indicated the formation of "dispersed" heterogeneities within the network structure. The presence of MMT prevented some recrystallization of the polymeric network, and the loss of water molecules allowed the amylose-sorbitol assemblage to form various domain sizes within the matrix since this behavior was not seen after the incorporation of $2 \mathrm{wt} \%$ MMT (sample OS220 in Figure 4(b). The heterogeneities in lamellar structure, which resulted from the different crystalline domains formed by the removal of weakly associated water molecules, are further discussed Section 3.2.4.

Some researchers [36] had reported that increasing the sorbitol amount could lead to a small reduction in the basal spacing due to the stronger interaction of water-sorbitol compared to water-MMT interaction. We found that this was true for the high-moisture-condition samples; for example, for $2 \mathrm{wt} \%$ MMT samples, the basal spacing reduced from $21.7 \AA$ to $20.8 \AA$, as the sorbitol was increased to $20 \mathrm{wt} \%$. But for the low equilibrium moisture content samples, we noted that no such dominant trend existed; the water molecules interacted with both sorbitol and with polymer chains depending upon the concentration of MMT. The deviation of the basal spacing for two sets of samples (denoted as $\Delta d$ in Table 1) decreased with the sorbitol concentration irrespective of the MMT loading.

3.2.3. Formation of V-Type Crystals. On top of the B-type crystals discussed in the previous sections, X-ray patterns for V-type starch crystal were observed in all the extruded amylose samples. This crystal consisted of the regular packing of ordered amylose single helix with a diameter of $1.3 \mathrm{~nm}$ [37] and $1.36 \mathrm{~nm}$ [38] for dehydrated and hydrated crystal, respectively $[39,40]$. The $\mathrm{V}$-type crystal peaks were assigned as $1.33 \mathrm{~nm}\left(Q=0.475 \AA^{-1}\right)$ and $1.28 \mathrm{~nm}(Q=$ $0.487 \AA^{-1}$ ) for the high- and low-moisture-content samples in the current study, as seen in the inset window in Figures 2 and 4 .

In summary, in the starch/water/sorbitol/MMT system, when the relative concentrations were not in excess, multiple interactions among different components coexisted: including the interactions between plasticizers such as water and sorbitol (acting as two competing plasticizers), the interactions between starch and plasticizers, and the interaction between starch and MMT, as well as the interactions between MMT and sorbitol/water. This will be further discussed Section 3.2.4.

\subsubsection{Size Distribution of the Various Crystalline Domains on} Ternary Composite Samples. Based on the theory of SAXS, the central condition for obtaining the size distribution information is the presence of heterogeneity in the electron density distribution on nanoscale [23]; thus, quantitative analysis could be carried out based on the obtained SAXS profiles. The obtained SAXS profiles for all the samples were analyzed using rod-like structure particle model (Unified Rod model, aspect ratio $=100)$ in the size distribution calculation $[41,42]$ to gain a better understanding of MMT intercalation/agglomeration. Unlike most polymer nanocomposite investigations, this study involved unmodified MMT mixed with sorbitol plasticizer to increase the effectiveness of the MMT platelets in hindering large-scale reorganization of amylose-sorbitol groups (and forming large domains). The size distribution calculation results are shown in Figure 5. Two well-defined domains were observed in the low-moisture-content samples, where the scatter diameters were denoted as $\bar{d}_{1 \text {-low }}$ (around $95 \AA$ ) and $\bar{d}_{2 \text {-low (around }}$ $310 \AA)$. However only one domain $\left(\bar{d}_{1 \text {-high }}\right)$ sized around $95 \AA$ was defined in the high-moisture-content samples.

The quantitative results of size distribution within these samples are tabulated in Table 2, where the normalized residuals for all the fittings were within $\pm 1 \AA$, suggesting a fairly good fitting. Table 2 shows two different size distribution profiles, where the mean scatter diameter for domain 1 ranged from $78.5 \AA$ to $104 \AA$ and $79.7 \AA$ to $100.8 \AA$ for the high-and low-moisture-content samples, respectively.

The mean diameter was obviously related to the sorbitol/MMT loading due to their strong interactions, and it was observed that the sorbitol-rich samples had a larger scatter diameter $\left(\bar{d}_{1-\text { high }}\right)$ in the high-moisture-content samples, (Table 2). However, for the low-moisture-content samples, the value of $\bar{d}_{1 \text {-low }}$ decreased with increasing the sorbitol amount.

The impact of modifying the MMT with the sorbitol plasticizer was seen in the limited long-range order achieved by the bionanocomposite matrix due to the typical interactions within "MMT-rich" environment [43] and the steric hindrances associated with a platelet-type structure. However in this study, it was interesting to note that the polymerMMT interactions were comparatively stronger with low sorbitol amounts, which led to a lower degree intercalated structure. This was reflected in the reduced scatter diameter upon changing the sorbitol concentration, as indicated by the size distribution results. This behavior was also seen in the representative TEM images (Figure 6), and they were the visual representation of MMT intercalation at both low sorbitol and high sorbitol concentration to compare the impact of excess plasticizer.

The observation of two domains could be correlated to the well-defined retrogradation phenomena, where the 
TABLe 2: Radius $(\AA)$ from size distribution calculated by MEM method for both the high- and low-moisture-content samples.

\begin{tabular}{|c|c|c|c|c|}
\hline \multicolumn{2}{|c|}{ High-moisture-content sample } & \multicolumn{3}{|c|}{ Low-moisture-content sample } \\
\hline Sample ID & $\bar{d}_{1 \text {-high }} *(\AA)$ & Sample ID & $\bar{d}_{\text {1-low }}{ }^{*}(\AA)$ & $\bar{d}_{2 \text {-low }}{ }^{*}(\AA)$ \\
\hline S105 & 94.1 & OS105 & 80 & 275.7 \\
\hline S115 & 104 & OS115 & 101.9 & 351.4 \\
\hline S200 & 96.1 & OS200 & 100.8 & 306 \\
\hline S210 & 99.3 & OS210 & 94 & 333.1 \\
\hline S220 & 102 & OS220 & 92.5 & 311.9 \\
\hline S305 & 93 & OS305 & 98.6 & 309.1 \\
\hline S315 & 97.7 & OS315 & 97.9 & 301.5 \\
\hline S400 & 78.5 & OS400 & 94.2 & 330.2 \\
\hline S410 & 95.4 & OS410 & 99.5 & 296.6 \\
\hline S420 & 97 & OS420 & 96 & 308.4 \\
\hline
\end{tabular}

${ }^{*} \bar{d}$ : mean scatter diameter $(\AA)$.

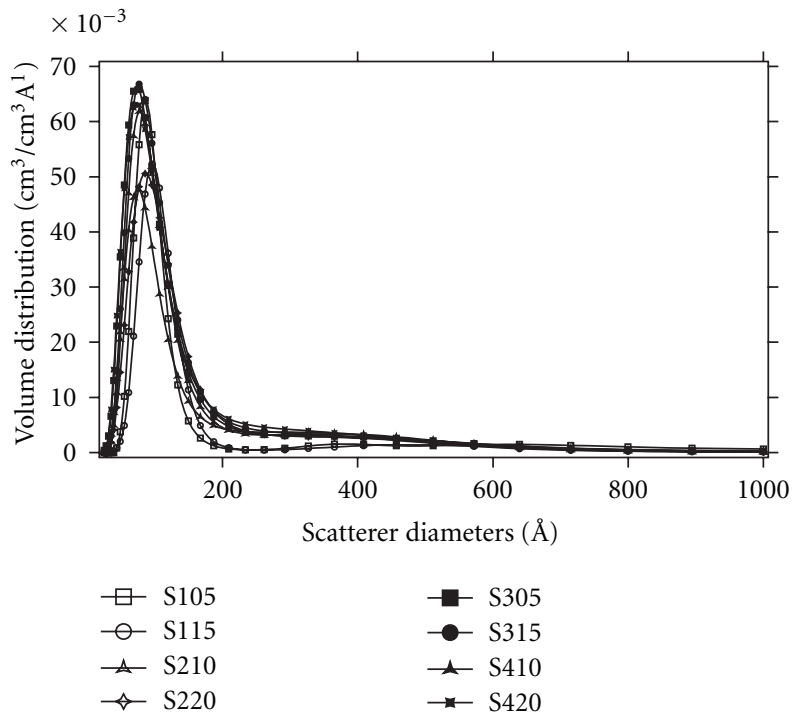

(a)

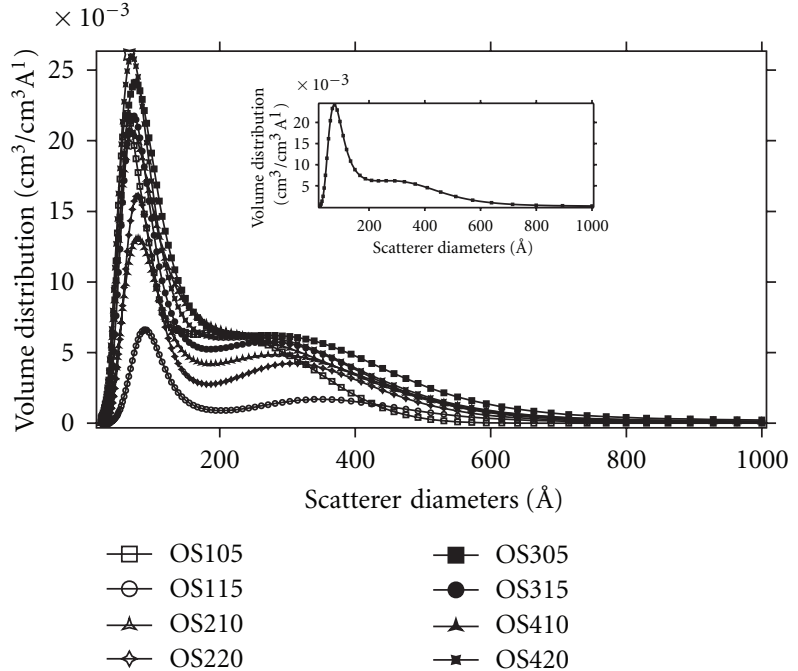

(b)

FIGURE 5: Size distribution calculation result via MEM method for starch/sorbitol/nanoclay nanocomposites (a) high-moisture-content samples and (b) low-moisture-content samples.

rearrangement of amylose chains typically dominates other processes [44, 45]. Schiraldi et al. [46] had discussed that the retrogradation behavior was hindered in the presence of excess sorbitol. However, the results shown here strongly suggested that different size domains coexisted within the samples even at a higher sorbitol concentration indicating the amylose retrogradation process. Thus, it was concluded that a combination of moisture and sorbitol concentration could effectively limit amylose-amylose interactions and prevent the formation of larger domains.

\subsection{Thermal Characterization Using Differential Scanning}

Calorimetry. Figure 7 compares the typical heat flow curve for amylose polymer and its bionanocomposites and outlines the impact of addition of MMT and sorbitol on the crystalline phase and the melting temperatures of the bionanocomposites.
The variation in peak width and height indicated that the crystallinity was significantly affected by the presence of sorbitol and MMT. In polymer-MMT systems, the endotherm peak can provide information on the crystalline phases in the nanocomposites when the MMT platelets have molecularlevel interactions within the polymer matrix. The SAXS data and TEM images had proved the existence of strong polymerMMT interactions and various levels of MMT intercalation within the bio-nanocomposites.

Comparing Figures 1 and 7, sample S200 showed that the addition of MMT led to the formation of a relatively ordered polymeric network (peak became sharper), and this strongly correlated with the corresponding diffraction pattern (elliptical SAXS pattern). Also, the melting temperature increased upon increasing the sorbitol concentration, even though the melting enthalpy remained comparable (comparable peak height and width), irrespective of the MMT content 


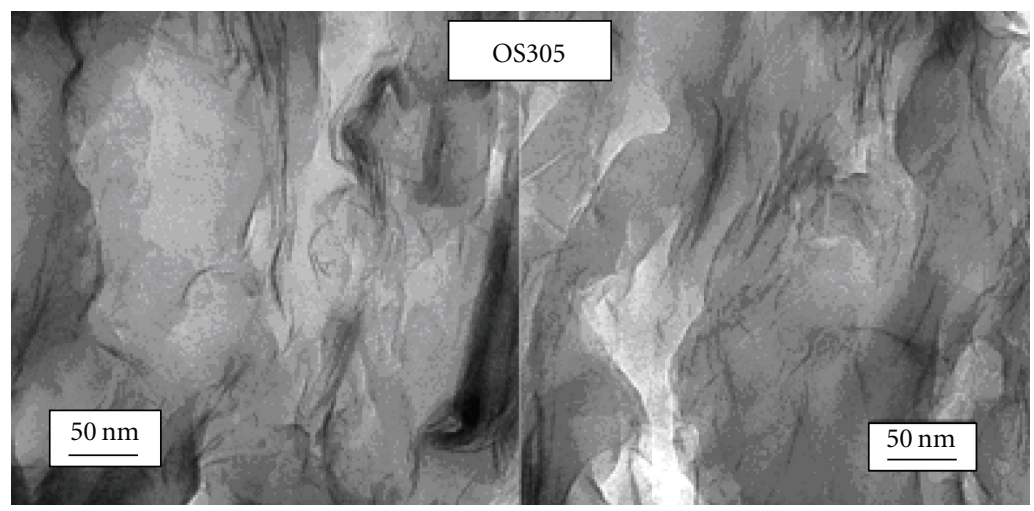

(a)

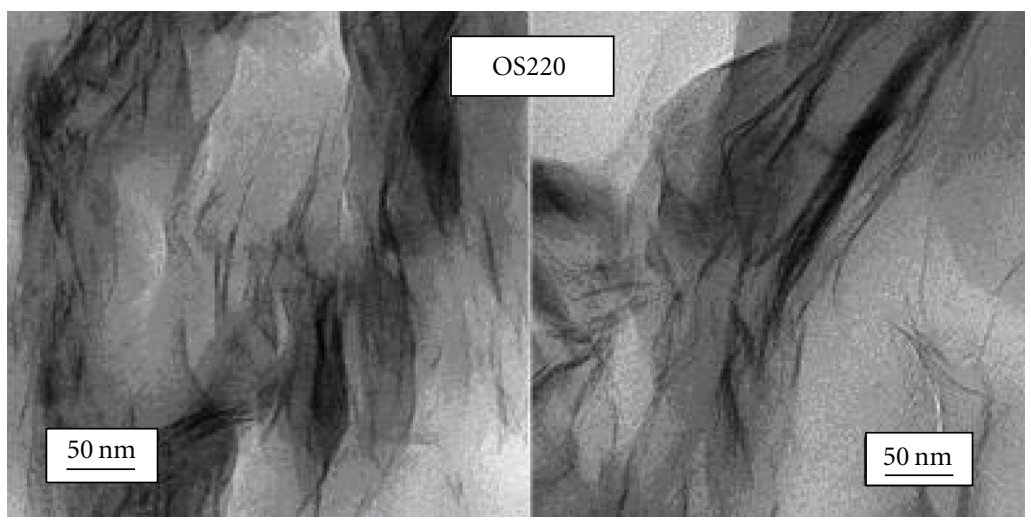

(b)

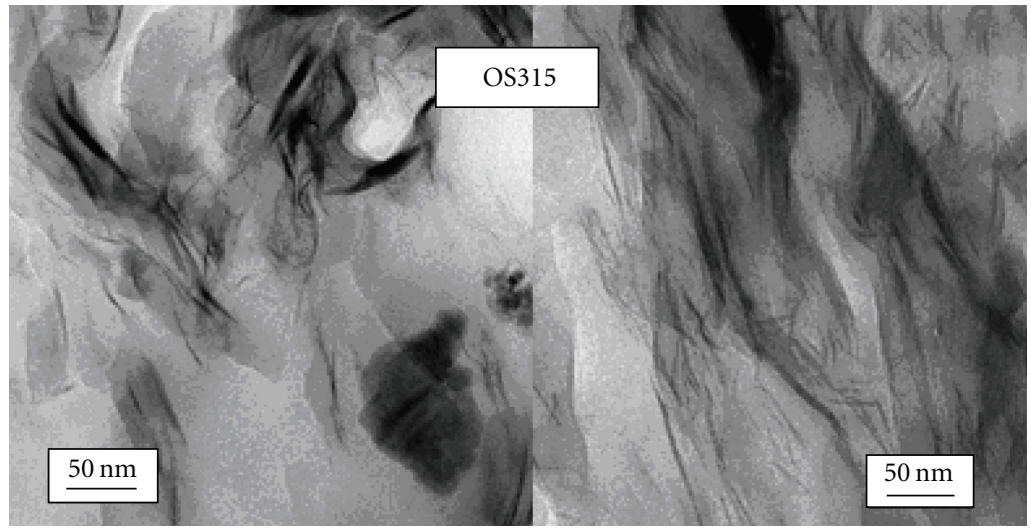

(c)

Figure 6: TEM image for representative samples, intercalation/exfoliation clearly coexisted.

(Figure 1 showed diffraction patterns with varied intensities and sharpness).

To improve the understanding of those interactions, the crystallization process was modeled by the Avrami equation [47] to investigate the nonisothermal crystallization kinetics [48]

$$
X_{t}=\frac{\int_{t_{0}}^{t}\left(d H_{c} / d t\right) d t}{\int_{t_{0}}^{t_{\infty}}\left(d H_{c} / d t\right) d t} .
$$

All the curves had a partial sigmoidal shape (not shown here), and an analysis of the development of the relative crystallinity was carried out using $X_{t}=1-\exp \left(-k t^{n}\right)$. A plot of $\log [-\ln (1-X t)]$ versus $\log (t)$ (Figure 8 ) provided the first parameter $n$, whose value depended upon the mechanics of nucleation and on the form of crystal growth, and the second parameter $k$, a rate constant containing the crystal growth parameters.

In Figure 8, nearly all the samples demonstrated one prominent linear region; however, the regions were distributed over different time lengths. This linearity reflected a large-scale homogeneous domain formed by the polymer/MMT intercalated regions. Further, the small changes 


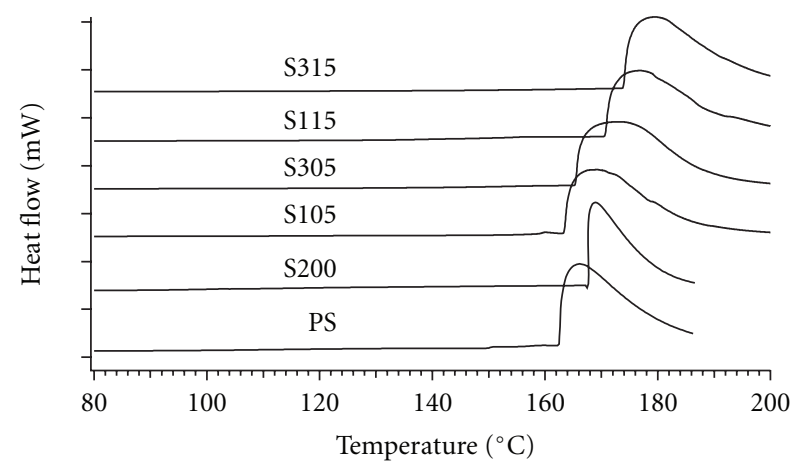

FIGURE 7: DSC heating curves (heating, endotherm-up) for selected samples with varying nanoclay and sorbitol content.

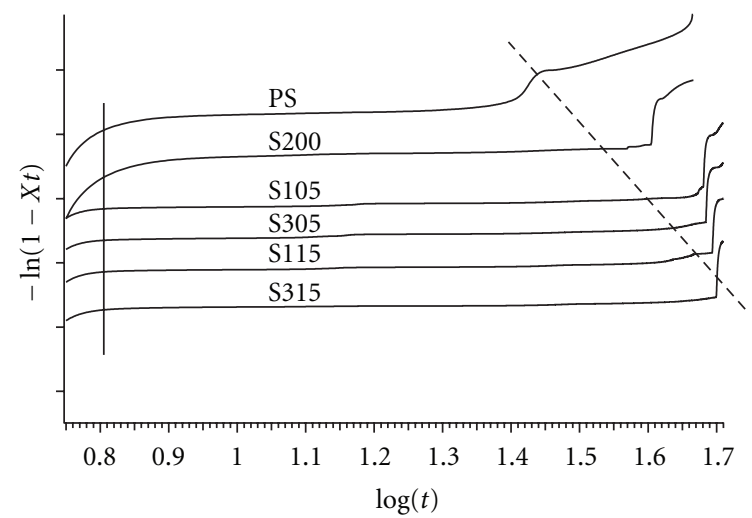

FIGURE 8: Decay of overall crystallinity based on the nonisothermal crystallization kinetics analysis using the modified Avrami equation. Plots are shown for key samples. All plots were corrected for the baseline and offset for clarity.

in the slope (Figure 8, region near the dashed line) indicated the presence of a small fraction of heterogeneous crystalline domain, and such heterogeneity was due to the typical secondary nucleation causing smaller imperfect crystals to form larger domains [49].

Moreover, Figure 8 shows the amylose crystallization kinetics, which emphasized the nucleation mechanism, and also shows significant deviation upon the addition of MMT (comparing PS to OS200) [50]. Two key points were highlighted from Figure 8: one, the interaction between sorbitol and MMT did not influence the onset temperature (shown by the vertical solid line) and two, the sorbitol had a greater influence on the development of heterogeneities within the crystalline domains (indicated by the slanted dashed line and its slope), as compared to the effect of MMT itself.

Finally, comparing $n$ and $k$, Table 3 for the samples with high and low equilibrium moisture content revealed the complex interactions that coexist in this system. As shown in Table 3 and Figure 9, the values of $n$ for all the high-moisture nanocomposites were overall smaller than those of the low-moisture nanocomposites. This indicated a tridimensional growth with heterogeneous nucleation where

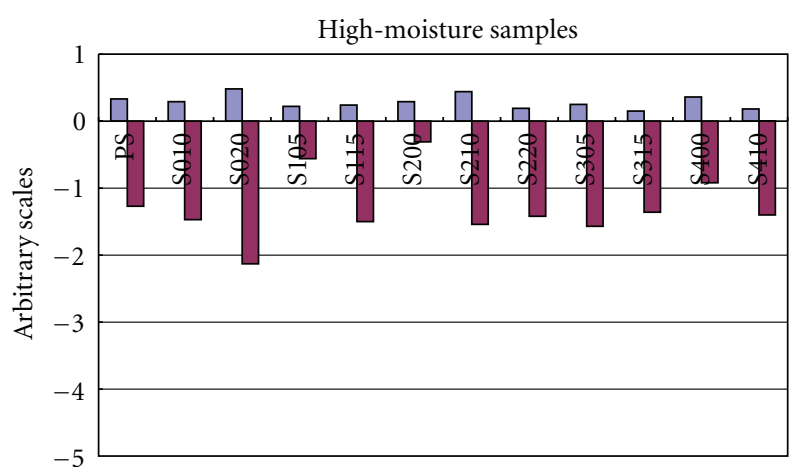

(a)

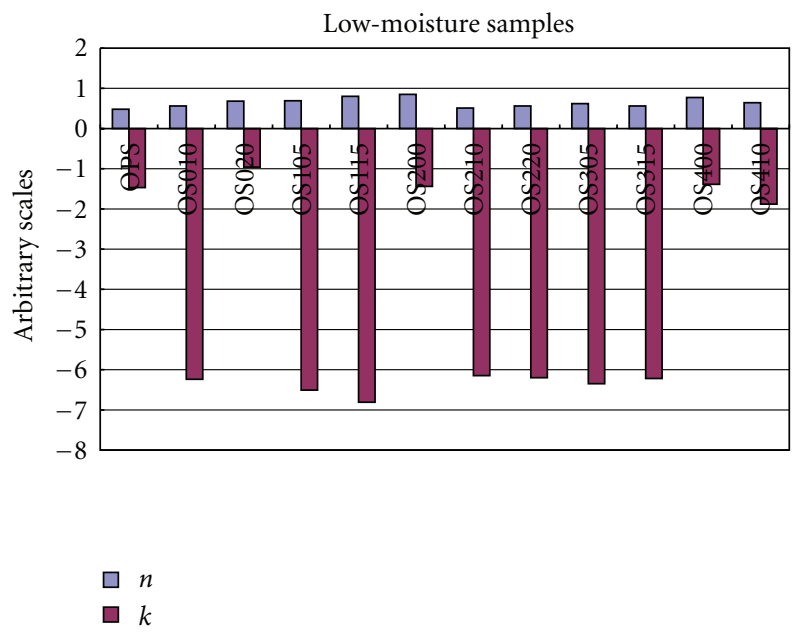

(b)

FIGURE 9: A barchart of the exponent $n$ and the factor $k$ obtained from a nonisothermal crystallization analysis. The $x$-axis represents the concentration of nanoclay and sorbitol only, without their prefix letter for sorbitol.

the interactions between water and amylose were replaced by sorbitol and amylose. This behavior was expected for the low-moisture-content samples since the removal of free water molecules restricted the mobility of starch polymer and weakened its ability to form highly ordered structure correspondingly. The finding of two domains in the low-moisture samples further supported this argument.

Further, the significance of water molecules in allowing crystalline fractions to grow was interpreted from the large variation in parameter $k$ values. Since the mobility of water molecules was higher than that of sorbitol (due to a smaller molecular size of water), the domain growth was expedited by the presence of sufficient water-amylose interactions. In other words, the chain mobility was a main factor that determined the $k$ parameter value; the larger $k$ value found for the high-sorbitol-content samples (S020 and S420) further suggested that higher-chain mobility can be obtained if enough sorbitol-amylose interactions took place, even in the presence of MMT. Such investigations are currently being carried out. 
TABLE 3: The exponent $n$ and the factor $k$ obtained from a nonisothermal crystallization analysis using the modified Avrami equation for all the samples.

\begin{tabular}{|c|c|c|c|c|c|}
\hline Sample ID & $n$ & $k$ & Sample ID & $n$ & $k$ \\
\hline PS & 0.33 & -1.27 & OPS & 0.48 & -1.47 \\
\hline S010 & 0.29 & -1.47 & OS010 & 0.56 & -6.24 \\
\hline S020 & 0.48 & -2.13 & OS020 & 0.68 & -0.96 \\
\hline S105 & 0.22 & -.56 & OS105 & 0.69 & -6.51 \\
\hline S115 & 0.24 & -1.5 & OS115 & 0.80 & -6.81 \\
\hline S200 & 0.29 & -.31 & OS200 & 0.85 & -1.44 \\
\hline S210 & 0.44 & -1.54 & OS210 & 0.51 & -6.15 \\
\hline S220 & 0.19 & -1.42 & OS220 & 0.56 & -6.2 \\
\hline S305 & 0.25 & -1.57 & OS305 & 0.62 & -6.35 \\
\hline S315 & 0.15 & -1.36 & OS315 & 0.56 & -6.22 \\
\hline S400 & 0.36 & -0.92 & OS400 & 0.77 & -1.39 \\
\hline S410 & 0.18 & -1.4 & OS410 & 0.64 & -1.88 \\
\hline S420 & 0.19 & -1.49 & OS420 & 1.11 & -1.84 \\
\hline
\end{tabular}

\section{Conclusions}

Small angle X-ray diffraction technique and calorimetric measurements were employed to ascertain the competitive nature of sorbitol-amylose interaction in both high-moisture and low-moisture conditions. To modify the plasticizer (sorbitol and water)-polymer interactions, the MMT was incorporated at various loading, and it was found that when the additives (plasticizers and MMT) were not in excess, the amylose crystalline domains exhibited different diffraction patterns due to the changes in MMT basal spacing and crystalline size distribution. Increasing the sorbitol content favored the polymer intercalation with the MMT rather than expanding the MMT basal spacing by greater sorbitolamylose interactions. B-type and V-type starch crystals were observed in all the extruded samples. The crystalline domain size could be altered depending on the relative concentrations of MMT and sorbitol plasticizers.

Variations in sorbitol-amylose interactions also caused the loss of water molecules from the matrix, and then the strong retrogradation characteristics of amylose suppressed the MMT basal spacing and the crystalline size radius of the crystalline domain. As a result, two different size domains (around $95 \AA$ and $310 \AA$ ) were found for the low-moisture samples; however, only one domain (around $95 \AA$ ) was evident for the high-moisture samples.

Together with the SAXS studies, the calorimetric analysis revealed the complex interactions between MMT and plasticizers (sorbitol and water), when the components were not in excess. Further, the packing of crystalline domains and the heterogeneous growth were influenced by the addition of MMT and its interaction with sorbitol, as revealed by the results of the nonisothermal crystallization kinetics analyzing. MMT predominantly influenced the packing of the crystalline domain, but presence of plasticizer helped maintain long-range order and greater heterogeneity, and these findings strongly correlated with the diffraction pattern results.

\section{Acknowledgments}

The authors wish to thank Dr. Kyuya Nakagawa at The University of Hyogo (Japan), for his excellent technical assistance with the SAXS experiment and acknowledge the internal funding from the Curtin University of Technology. Ms. H. Liu also wishes to thank the Hyogo prefecture for the student exchange scholarship (HUMAP). There is no potential conflict of interests among the researchers, and this investigation does not bias any other investigation.

\section{References}

[1] A. L. Chaudhary, P. J. Torley, P. J. Halley, N. McCaffery, and D. S. Chaudhary, "Amylose content and chemical modification effects on thermoplastic starch from maize-processing and characterisation using conventional polymer equipment," Carbohydrate Polymers, vol. 78, no. 4, pp. 917-925, 2009.

[2] D. S. Chaudhary and B. P. Adhikari, "Understanding polymeric amylose retrogradation in presence of additives," Journal of Applied Polymer Science, vol. 115, no. 5, pp. 2703-2709, 2010.

[3] D. S. Chaudhary, B. P. Adhikari, and S. Kasapis, "Glasstransition behaviour of plasticized starch biopolymer system-a modified Gordon-Taylor approach," Food Hydrocolloids, vol. 25, no. 1, pp. 114-121, 2011.

[4] D. S. Chaudhary, H. Liu, and B. Adhikari, "Influence of branching and plasticiser on water activity in starch biopolymer," in 30th Australasian Polymer, p. 151, Melbourne, Australia, 2008.

[5] H. Liu, D. Chaudhary, S. I. Yusa, and M. O. Tadé, "Glycerol/ starch/ $\mathrm{Na}^{+}$-montmorillonite nanocomposites: a XRD, FTIR, DSC and 1H NMR study," Carbohydrate Polymers, vol. 83, no. 4, pp. 1591-1597, 2011.

[6] D. S. Chaudhary, "Understanding amylose crystallinity in starch-clay nanocomposites," Journal of Polymer Science, Part B: Polymer Physics, vol. 46, no. 10, pp. 979-987, 2008.

[7] R. J. Roe, Methods of X-Ray and Neutron Scattering in Polymer Science, Oxford University Press, New York, NY, USA, 2002. 
[8] O. Glatter, "Evaluation of small-angle scattering data from lamellar and cylindrical particles by the indirect transformation method," Journal of Applied Crystallography, vol. 13, no. 6, pp. 577-584, 1980.

[9] F. J. Balta-Calleja and C. G. Vonk, X-Ray Scattering of Synthetic Polymers, Elsevier, New York, NY, USA, 1989.

[10] B. S. Hsiao and R. K. Verma, "A novel approach to extract morphological variables in crystalline polymers from timeresolved synchrotron SAXS data," Journal of Synchrotron Radiation, vol. 5, no. 1, pp. 23-29, 1998.

[11] K. Dean, L. Yu, and D. Y. Wu, "Preparation and characterization of melt-extruded thermoplastic starch/clay nanocomposites," Composites Science and Technology, vol. 67, no. 3-4, pp. 413-421, 2007.

[12] V. P. Cyras, L. B. Manfredi, M. T. Ton-That, and A. Vázquez, "Physical and mechanical properties of thermoplastic starch/montmorillonite nanocomposite films," Carbohydrate Polymers, vol. 73, no. 1, pp. 55-63, 2008.

[13] K. M. Dean, M. D. Do, E. Petinakis, and L. Yu, "Key interactions in biodegradable thermoplastic starch/poly(vinyl alcohol)/montmorillonite micro- and nanocomposites," Composites Science and Technology, vol. 68, no. 6, pp. 1453-1462, 2008.

[14] K. Inoue et al., "Present status of BL40B2 and BL40XU at SPring-8 (Beamlines for small angle X-Ray scattering)," in Proceedings of the 80th International Conference on Synchrotron Radiation Instrumentation, San Francisco, Calif, USA, 2004.

[15] C. S. Kealley, M. M. Elcombe, R. Wuhrer, and E. P. Gilbert, "Application of small-angle scattering to study the effects of moisture content on a native soy protein," Journal of Applied Crystallography, vol. 41, no. 3, pp. 628-633, 2008.

[16] J. A. Potton, G. J. Daniell, and B. D. Rainford, "A new method for the determination of particle size distributions from smallangle neutron scattering measurements," Journal of Applied Crystallography, vol. 21, no. 6, pp. 891-897, 1988.

[17] J. Ilavsky and P. R. Jemian, "Irena: tool suite for modeling and analysis of small-angle scattering," Journal of Applied Crystallography, vol. 42, no. 2, pp. 347-353, 2009.

[18] H. Liu, D. Chaudhary, S.-I. Yusa, and M. O. Tadé, "Preparation and characterization of sorbitol modified nanoclay with high amylose bionanocomposites," Carbohydrate Polymers, vol. 85, no. 1, pp. 97-104, 2011.

[19] H. Liu and D. Chaudhary, "The Moisture Migration Behavior of Plasticized Starch Biopolymer," Drying Technology, vol. 29, no. 3, pp. 278-285, 2011.

[20] H. Eslami, M. Grmela, and M. Bousmina, Structure and Rheology Correlation in Polymer Nanocomposites, Society of Plastics Engineers, Newtown, UK, 2009.

[21] L. E. Alexander, X-Ray Diffraction Methods in Polymer Science, Wiley-Interscience, New York, NY, USA, 1969.

[22] M. Kakapos and N. Kasai, X-Ray Diffraction by Polymers, Kodansha, Tokyo, Japan, 1972.

[23] B. Chu and B. S. Hsiao, "Small-angle X-Ray scattering of polymers," Chemical Reviews, vol. 101, no. 6, pp. 1727-1761, 2001.

[24] D. T. Grubb and N. S. Murthy, "Real-time X-Ray study of nylon-6 fibers during dehydration: equatorial small-angle scattering is due to surface refraction," Macromolecules, vol. 43, no. 2, pp. 1016-1027, 2010.

[25] H. Lemke, M. Burghammer, D. Flot, M. Rössle, and C. Riekel, "Structural processes during starch granule hydration by synchrotron radiation microdiffraction," Biomacromolecules, vol. 5, no. 4, pp. 1316-1324, 2004.
[26] K. Shamai, E. Shimoni, and H. Bianco-Peled, "Small angle XRay scattering of resistant starch type III," Biomacromolecules, vol. 5, no. 1, pp. 219-223, 2004.

[27] A. M. Donald, "Plasticization and self assembly in the starch granule," Cereal Chemistry, vol. 78, no. 3, pp. 307-314, 2001.

[28] A. Sarko and H. C. H. Wu, "The crystal structures of A-, B-and C-polymorphs of amylose and starch," Starch-Stärke, vol. 30, no. 3, pp. 73-78, 1978 .

[29] A. Lopez-Rubio, A. Htoon, and E. P. Gilbert, "Influence of extrusion and digestion on the nanostructure of high-amylose maize starch," Biomacromolecules, vol. 8, no. 5, pp. 1564-1572, 2007.

[30] A. Buleon et al., "Evolution of crystallinity and specific gravity of potato starch versus water ad-and desorption," StarchStärke, vol. 34, no. 11, pp. 361-366, 1982.

[31] R. Cleven, C. Van den Berg, and L. Van Der Plas, "Crystal structure of hydrated potato starch," Starch-Stärke, vol. 30, no. 7, pp. 223-228, 1978.

[32] B. S. Chiou, D. Wood, E. Yee, S. H. Imam, G. M. Glenn, and W. J. Orts, "Extruded starch-nanoclay nanocomposites: effects of glycerol and nanoclay concentration," Polymer Engineering and Science, vol. 47, no. 11, pp. 1898-1904, 2007.

[33] X. Tang, S. Alavi, and T. J. Herald, "Effects of plasticizers on the structure and properties of starch-clay nanocomposite films," Carbohydrate Polymers, vol. 74, no. 3, pp. 552-558, 2008.

[34] E. Rinnert, C. Carteret, B. Humbert et al., "Hydration of a synthetic clay with tetrahedral charges: a multidisciplinary experimental and numerical study," Journal of Physical Chemistry B, vol. 109, no. 49, pp. 23745-23759, 2005.

[35] A. M. Donald, "Plasticization and self assembly in the starch granule," Cereal Chemistry, vol. 78, no. 3, pp. 307-314, 2001.

[36] S. A. McGlashan and P. J. Halley, "Preparation and characterisation of biodegradable starch-based nanocomposite materials," Polymer International, vol. 52, no. 11, pp. 17671773, 2003.

[37] V. G. Murphy, B. Zaslow, and A. D. French, "The structure of $\mathrm{V}$ amylose dehydrate: a combined X-Ray and stereochemical approach," Biopolymers, vol. 14, no. 7, pp. 1487-1501, 1975.

[38] J. Brisson, H. Chanzy, and W. T. Winter, "The crystal and molecular structure of $\mathrm{V}(\mathrm{H})$ amylose by electron diffraction analysis," International Journal of Biological Macromolecules, vol. 13, no. 1, pp. 31-39, 1991.

[39] H. A. Pushpadass and M. A. Hanna, "Age-induced changes in the microstructure and selected properties of extruded starch films plasticized with glycerol and stearic acid," Industrial and Engineering Chemistry Research, vol. 48, no. 18, pp. 8457-8463, 2009.

[40] J. J. G. Van Soest and P. Essers, "Influence of amylose-amylopectin ratio on properties of extruded starch plastic sheets," Journal of Macromolecular Science Part A, vol. 34, no. 9, pp. 1665-1689, 1997.

[41] G. Beaucage, "Approximations leading to a unified exponential/ power-law approach to small-angle scattering," Journal of Applied Crystallography, vol. 28, no. 6, pp. 717-728, 1995.

[42] S. Pikus, "Small-angle X-Ray scattering (SAXS) studies of the structure of starch and starch products," Fibres and Textiles in Eastern Europe, vol. 13, no. 5, pp. 82-86, 2005.

[43] Y. Vodovotz and P. Chinachoti, "Glassy-rubbery transition and recrystallization during aging of wheat starch gels," Journal of Agricultural and Food Chemistry, vol. 46, no. 2, pp. 446-453, 1998.

[44] I. A. Farhat, J. M. V. Blanshard, and J. R. Mitchell, "The retrogradation of waxy maize starch extrudates: effects of storage temperature and water content," Biopolymers, vol. 53, no. 5, pp. 411-422, 2000. 
[45] W. G. Hoover, "Starch retrogradation," Food Reviews International, vol. 11, no. 2, pp. 331-346, 1995.

[46] A. Schiraldi, L. Piazza, and M. Riva, "Bread staling: a calorimetric approach," Cereal Chemistry, vol. 73, no. 1, pp. 32-39, 1996.

[47] S. W. Lee, M. Ree, C. E. Park et al., "Synthesis and non-isothermal crystallization behaviors of poly(ethylene isophthalate-co-terephthalate)s," Polymer, vol. 40, no. 25, pp. 7137-7146, 1999.

[48] D. S. Chaudhary, R. Prasad, R. K. Gupta, and S. N. Bhattacharya, "Clay intercalation and influence on crystallinity of EVA-based clay nanocomposites," Thermochimica Acta, vol. 433, no. 1-2, pp. 187-195, 2005.

[49] Y. Li, G. Zhang, X. Zhu, and D. Yan, "Isothermal and nonisothermal crystallization kinetics of partially melting nylon 10 12," Journal of Applied Polymer Science, vol. 88, no. 5, pp. 1311-1319, 2003.

[50] D. S. Chaudhary, M. C. Jollands, and F. Cser, "Crystallinity of polypropylene-silica ash composites affected by the mixing conditions-DSC studies," Polymers and Polymer Composites, vol. 12, no. 5, pp. 383-398, 2004. 

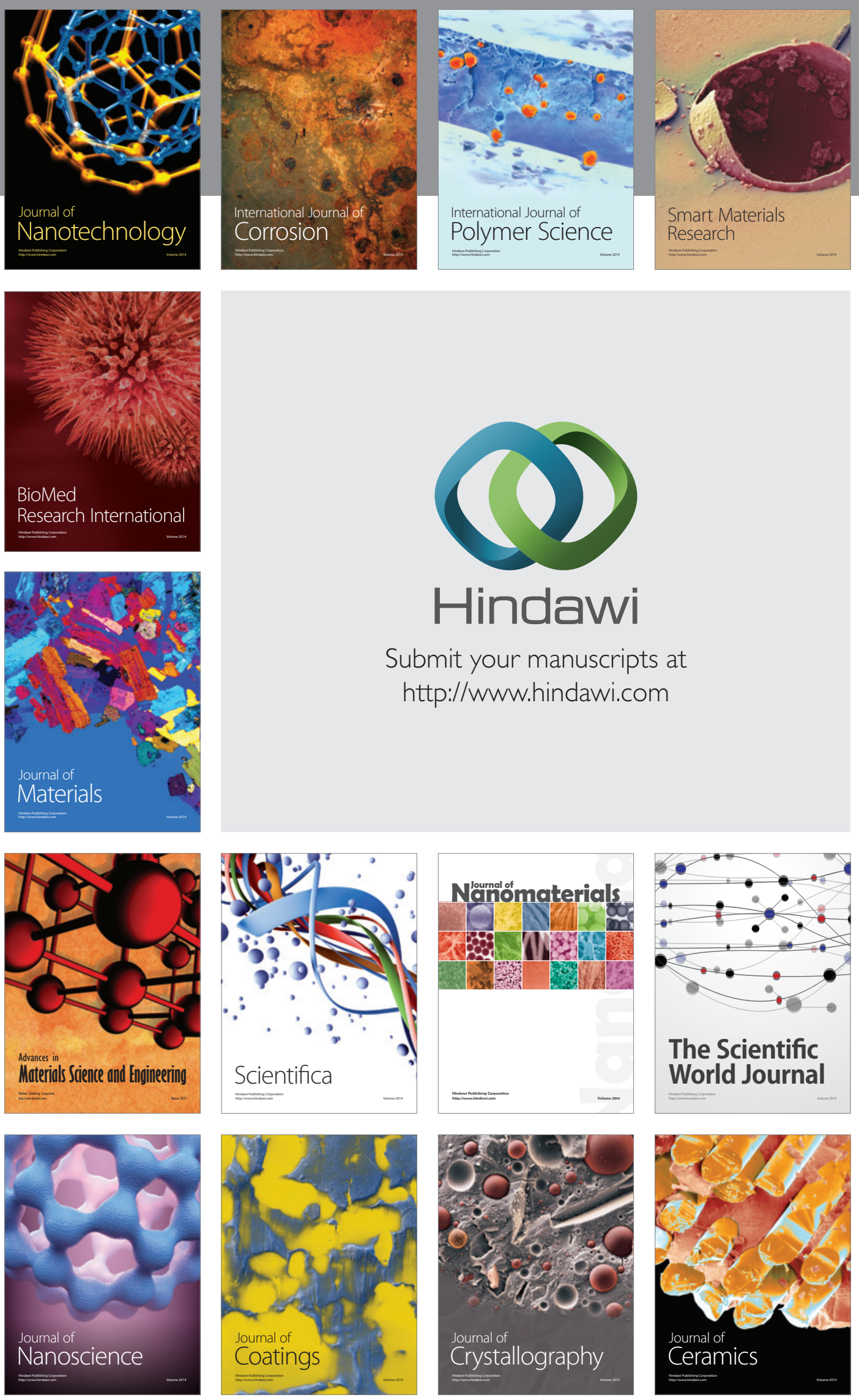

The Scientific World Journal

Submit your manuscripts at

http://www.hindawi.com

\section{World Journal}

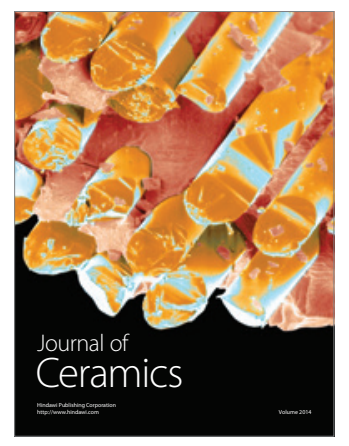

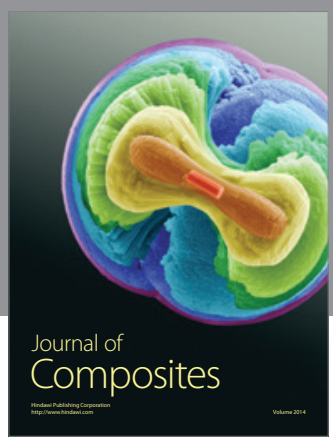
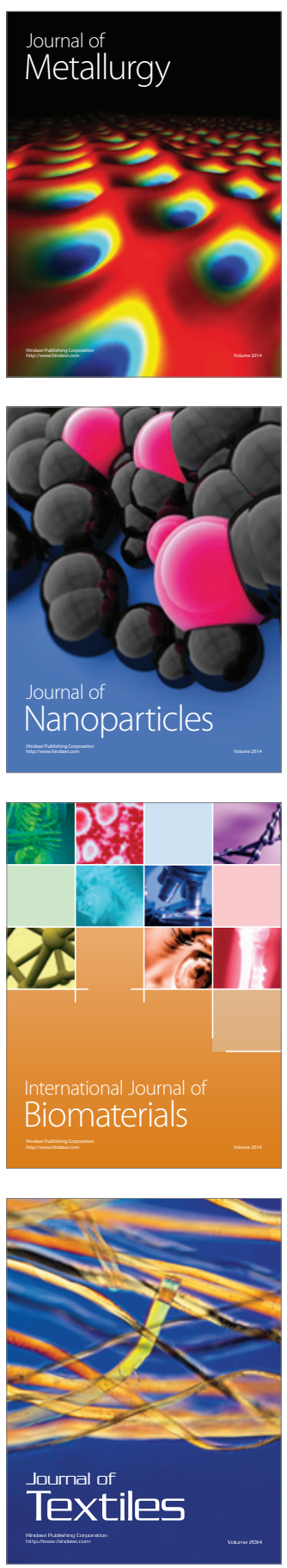